\title{
WEIGHTED INEQUALITIES RELATED TO A MUCKENHOUPT AND WHEEDEN PROBLEM FOR ONE-SIDE SINGULAR INTEGRALS
}

\author{
María Silvina Riveros and Raúl EMilio Vidal
}

\begin{abstract}
In this paper we obtain for $T^{+}$, a one-sided singular integral given by a CalderónZygmund kernel with support in $(-\infty, 0)$, a $L^{p}(w)$ bound when $w \in A_{1}^{+}$. In [A. K. Lerner, S. Ombrosi and C. Pérez, $A_{1}$ Bounds for Calderón-Zygmund operators related to a problem of Muckenhoupt and Wheeden, Math. Res. Lett. 16 (2009), no. 1, 149-156.], the authors proved that this bound is sharp with respect to $\|w\|_{A_{1}}$ and with respect to $p$. We also give a $L^{1, \infty}(w)$ estimate, for a related problem of Muckenhoupt and Wheeden for $w \in A_{1}^{+}$. We improve the classical results, for one-sided singular integrals, by putting in the inequalities a wider class of weights.
\end{abstract}

Mathematics subject classification (2010): 42B20, 42B25.

Keywords and phrases: One-sided singular integrals, Sawyer weights, weighted norm inequalities.

\section{REFERENCES}

[1] H. Aimar, L. ForZAni And F. J. Martín-Reyes, On weighted inequalities for singular integrals, Proceedings of the American Mathematical Society, 125, (1997), 2057-2064.

[2] S. M. BUCKLEY, Estimates fro operator norms on weighted spaces and reverse Jensen inequalities, Trans. Amer. Math. Soc., 340 no. 1, (1993), 253-272.

[3] L. CARLESON, On convergence and growth of partial sums of Fourier series, Acta Math. 116, (1966), $135-157$.

[4] O. Dragičević, L. Grafakos, M. C. Pereyra and S. Petermichl, Extrapolation and sharp norm estimates for classical operators on weighted Lebesgue spaces, Publ. Math., 49 no. 1, (2005), 73-91.

[5] C. Fefferman, E. M. Stein, Some maximal inequalities, Amer. Jour. Math. 93, (1971), 107-115.

[6] J. García-Cuerva AND J. L. Rubio De Francia, Weighted Norm Inequalities and Related Topics, North Holland Mathematics Studies 116, (1985).

[7] T. HytÖNEN, M. LACEY AND C. PÉREZ, Sharp weighted bounds for the q-variation of singular integrals, Bulletin London Math. Soc. (2013); doi: 10.1112/blms/bds114.

[8] T. Hytönen And C. PÉREZ, Sharp weighted bounds involving $A_{\infty}$, Analysis and PDE 6, no 4, (2013) 777-818.

[9] T. Hytönen, C. PÉREZ And E. Rela, Sharp Reverse Hölder property for $A_{\infty}$ weights on spaces of homogeneous type, Journal of Functional Analysis 263, (2012) 3883-3899.

[10] A. K. Lerner, S. Ombrosi, AND C. PÉREZ, Sharp $A_{1}$ bounds for Calderón-Zygmund operators and the relationship with a problem of Muckenhoupt and Wheeden, Int. Math. Res. Not. IMRN 2008, no. 6, Art. ID rnm161, 11 pp.

[11] A. K. LERNER, S. OMBrosi, AND C. PÉREZ, $A_{1}$ Bounds for Calderón-Zygmund operators related to a problem of Muckenhoupt and Wheeden, Math. Res. Lett. 16 no. 1, (2009), 149-156.

[12] M. Lorente, J. M. Martell, C. PÉReZ And M. S. Riveros, Generalized Hörmander condition and weighted endpoint estimates, Studia Math. 195 no 2, (2009), 157-192.

[13] F. J. MARTíN-REYES, New proofs of weighted inequalities for the one-sided Hardy-Littlewood functions, Proceedings for the American Mathematical Society, 117, (1993), 691-698.

[14] F. J. MARTín-Reyes, P. ORTEga AND A. DE LA TORRE, Weighted inequalities for one-sided maximal functions, Trans. Amer. Math. Soc. 319, (1990), 517-534. 
[15] F. J. Martín-Reyes, L. Pick and A. De La Torre, $A_{\infty}^{+}$Condition, Can. J. Math. 45 no 6, (1993), $1231-1244$.

[16] F. J. MARTín-REYeS AND A. DE LA TORRE, Two weight norm inequalities for fractional one-sided maximal operators, Proceedings of the American Mathematical Society. 117, (1993), 483-489.

[17] F. J. MARTín-REYES AND A. DE LA TORRE, Sharp weighted bounds for one-sided maximal operators, to appear in Collectanea Mathematica, 2015.

[18] B. Muckenhoupt, R. Wheeden, Personal communication to C. Pérez.

[19] F. Nazarov, A. Reznikov, V. VASYunin, A. VolberG, Weak norm estimates of weighted singular operators and Bellman functions, Preprint, http://sashavolberg.files.wordpress.com/ 2010/11/a11_7loghilb11_21_2010.pdf.

[20] C. PÉREZ, Weighted norm inequalities for singular integral operators, J. London Math. Soc., 49, (1994), 296-308.

[21] C. PÉREZ, Personal communication.

[22] M. C. Reguera, On Muckenhoupt-Wheeden conjecture, Adv. Math. 227, No. 4, (2011), 1436-1450.

[23] M. C. Reguera And C. Thiele, The Hilbert transform does not map $L^{1}(M w)$ to $L^{1, \infty}(w)$, Math. Res. Lett. 19 (2012), no. 1, 1-7.

[24] M. S. Riveros AND A. DE LA TorRe, On the best ranges for $A_{p}^{+}$and $R H_{r}^{+}$, Czechoslovak Mathematical Journal, 51 (126), (2001), 285-301.

[25] E. SAWYER, Weighted inequalities for the one-sided maximal Hardy Littlewood maximal functions, Trans. Amer. Math. Soc. 297, (1986), 53-61.

[26] E. Stein And G. Weiss, Introduction to Fourier analysis on Euclidean spaces, Princeton University Press., (1975). 